\title{
The Impact of Urban Agriculture on Students' Life Satisfaction in Eastern Cape, South Africa
}

Prof Emmanuel O.Adu Ph.D.

\author{
Faculty of Education, University of Fort Hare, East London, South Africa \\ eadu@ufh.ac.za
}

\author{
Mrs Beni Ntombomzi \\ Faculty of Education, University of Fort Hare, East London, South Africa \\ ntombomzibeni@gmail.com
}

Dr Titi Oshati Ph.D.

Federal Productivity Centre, Federal Secretariat Ibadan, Oyo State, Nigeria

oshatiti@yahoo.com

Doi:10.5901/mjss.2014.v5n23p1293

\begin{abstract}
The importance of agricultural sciences in the school curriculum all over the world cannot be over -emphasized .It include an alternative source of fresh produce, improved life satisfaction and a way to preserve cultural identity and traditions. This study tends to investigate more role of unban agriculture in relation to life satisfaction. The study reveals among others some components of life satisfaction as a result of urban agriculture. These components are; nutrition, self-employment, food security and poverty eradication. The study does not leave behind the economic benefits of urban agriculture such as; income distribution, small scale business to mention a few. The study however recommended among others that the South Africa Government should make agriculture education as a compulsory subject for grade 10 and grade 11 students. This will enable them to develop entrepreneurial skills and self-sufficient mentality before they finish their secondary school careers. The subject will also help them in building job skills, improving self-esteem and contributing to community revitalization. Similarly, the practical components of this subject should constitute $50 \%$ if not more from the overall marks. Hence, leaving secondary schools will no longer be a mirage and nightmare all because of no employment. However, some challenges were highlighted this include; limited spaces available, damage to sacks and crops by stray animals, pest and diseases, sustainable access to inputs such as soil, manure, seedlings and water.
\end{abstract}

Keywords: Urban Agriculture, Students, Nutrition, Poverty eradication, Food security, Small business scale.

\section{Introduction}

Urban agriculture is among the crucial issues to be addressed by educators and researchers. It has been observed that in terms of its significance at the level of the family welfare and satisfaction, cultivation of urban lands has a direct benefit in improving the lives of the poor.Poor children have numerous disadvantages in relation to their better off counterparts The effects of agricultural education on urban high school student's life satisfaction cannot be over emphasized. The introduction of agricultural education course in South African schools has brought another dimension into the mentality of the students. Urban agriculture is expected to reduce poverty and promote food security across the nation. The impact of urban agriculture on student's life satisfaction can help by providing students the connections with their food and understand of the nutritional and entrepreneurial aspects of the agriculture industry.

Food is at the centre of many cultures, world human population is growing exponentially to reach 9 billion by 2050 and the current agricultural system will not be able to sustain it (Tracey, 2011) There is no movement to grow more food in cities, where the majority of the world population lives, to reduce environmental impacts of industrial agriculture on nonurban while providing equitable access to affordable, fresh food across community lines in the developing world. Urban agriculture can reflect varying levels of economic and social development. In the Eastern Cape it can often takes the form of a social movement for sustainable communities, where organic growers, foodies form social networks. 
These networks can involve when receiving formal institutional support, becoming integrated into local town planning as transition town movement for sustainable urban development. In the developing countries, food security, nutrition, poverty eradication, and self-employment are key motivation for the practise.

Generally speaking, the importance of agricultural sciences in the school curriculum all over the world cannot be over -emphasized .It include an alternative source of fresh produce ,improved life satisfaction and a way to preserve cultural identity and traditions. Most importantly, urban agriculture can serve as a tool in securing food security and positive health outcomes for underserved communities .Urban agriculture may be done on land owned by a community group, institutions, municipality, land trust, or some other entity food grown on these plots can be kept for personal consumption or used to procure supplemental income. Additional benefits of urban agriculture beyond food provision include building job skills, improving self-esteem and contributing to community revitalization. School gardens can be a tool to prevent or delay hunger among students in Eastern Cape. Improving nutrition, increasing physical activity, increasing income and creating a positive mental outlook are other benefits of school gardens. Using gardening to change lives of the students is very imperative at this stage in South Africa.

The experience of growing food is correlated with its consumption, the more experience students have growing food, the more likely they are to eat it .Urban gardening builds safe, healthy and green environments in school .The studies pointed that the food system is a really clear way that it affects student and everyone because everyone eats (Rene, 2006). Students are not of exemption either they leave caring about food or not, they hopefully leave as more engaged citizens. They will see themselves as agents of change; they can affect change in their own lives, the lives of their family and of their community. Rene explains why food works so well as the particular focus for her deeper interests in addressing injustice and inequality. Food's a really good way to bring people from all different backgrounds together, particularly since it is a pivotal part of people's lives. Building trust through relationships centred on food becomes the vehicle for exploring poverty, racism, class, and justice. Students must be well prepared in the discovery of agricultural science, teaching and learning, in fact, the need to provide a highly educated, skilled workforce capable of providing solutions to $21^{\text {st }}$ century challenges and issues has never been greater. There is a growing need to develop strategies to create a society of diverse, highly educated professionals at all levels to address those challenges and develop innovations that drive economic growth (David, 2011)

In addition to an abundance of agricultural jobs, there are not enough individuals studying agriculturally related careers and there is no determined path to fix this problem (Higgins et al ,2011) According to the Coalition for a Sustainable Agricultural Workforce, three major obstacles exist in recruiting people into careers in agriculture, including budget constraints, student misconceptions, and competition for the most talented people from science and industry (Weed Science Society of America) However ,with so few schools serving rural communities, what role do school-based agricultural education classes play in urban high schools in encouraging students to pursue agriculture careers of their choice. What encourages students to and discourages students from pursuing agricultural careers allows practitioners to make modifications on a personal level concerning what is taught in classroom, without losing the integrity of the information taught in those courses

Urban agriculture is thought to increase food security through two main pathways: improved access to food, and increased income. Home-grown foodstuffs increase the total amount of food available to a household and thus can prevent hunger and malnutrition. At the same time the availability of fresh, home grown food products, in particular fruits and vegetables, advances the nutritional status of household members and thereby improves health. Direct access to food often allows particularly poor households to consume a more diverse diet than they would otherwise be able to afford. Especially, animal husbandry is believed to provide an important source of animal protein, which is commonly limited in poor households' diets due to income constraints

Urban Agriculture is now a component of many countries' socioeconomic development agencies. For urban Agriculture to make a meaning contribution to development, particularly in South Africa where chronic poverty persists, it must present viable sustainable business opportunities addition to its established social benefits. Millions of South Africans suffer educational and skills deficits, chronic unemployment and spatial segregation all of which have kept them at the margins of society and the economy (David, 2009). This set of circumstances has a devastating impact on poor people's life choices and opportunities, otherwise known as their agency (Axumite, 1994)

Development efforts in South Africa therefore must be aimed not only at economic growth but also at improving poor people's agency through real skill-building, developing income -earning opportunities and creating links from margins to the formal economy (Mougeot, 2006). The current South African government recently released its National Development Plan entitled Vision 2030 whose goals include reducing poverty and inequality and growing a more inclusive economy. This proposal represents a starting point in an exciting process of operationalizing a cross-sectorial research for development program on agriculture for improved nutrition, self-employment, food security and poverty, 
urban agriculture makes a contribution to the community and derives economic significance.

\section{The Emergence of Urban Agriculture}

The twenty-first century has often been described as 'the first urban century'. Unprecedented rural-urban migration has led to rapid urban growth. Whilst in 1900 a mere 13 per cent of the world's population lived in urban areas, the UNHabitat estimates that by 2030 this level will have risen to 60 per cent. Furthermore, virtually all of this population growth over the next few decades will be absorbed by cities in low and middle-income countries, thus increasing the pressure on urban resources and administrations that are often already exhausted

Among the most pressing needs of any urban agglomeration is the question of urban food security and ensuring the right to food. Urban populations depend on the reliable and stable availability of food products, as well as affordable and convenient access to them. High levels of urban income poverty paired with rising food prices, however, often make the formal urban food supply system unaffordable and inaccessible to the urban poor. An informal supply system, consisting of street vendors, informal markets, home-based enterprises as well as urban agriculture (UA), exists alongside formal interventions. These informal networks predominantly satisfy the urban poor's demand for easily accessible - though not often cheaper- foodstuffs

\section{Approaches to Urban Agriculture}

Whilst urban decision makers and academics alike have identified UA as the most beneficial and promising pillar of informal food supply systems the evidence for such claims is unclear. Although UA has been an integral part of urban livelihoods throughout human history, the concept only came to the fore in the late 1980s/early 1990s, evoking interest among international donors and development practitioners. A United Nations Development Program (UNDP) report estimated that it reached, in the early 1990s, some 800 million urban dwellers that used UA as a livelihood strategy. Some scholars even argue that UA presented some kind of a 'magic bullet' or panacea to eradicate hunger and poverty in urban areas. (Stephan \& David, 2012)

\section{Some Major Contributions of Urban Agriculture}

\subsection{Nutrition}

Nutrition, the process of providing or obtaining the food necessary for health and growth. Hunger, malnutrition and poor health are widespread and stubborn development challenges in the South Africa. Agriculture has made remarkable advances in the past decades, but progress in improving the nutrition and health of poor people living in South Africa is trailing behind which directly affects the students. Two urgent needs for the poor are better nutrition and better health. In its new vision with the students we are desperately seeking the strategy to reduce poverty and hunger, improving human health and nutrition. Innovations and best practices in urban nutrition, high rural-urban migration, high population growth rate, increasing vulnerability levels, rising food pricing and poor coping mechanisms in South Africa (Rene, 2006). In some schools in South Africa, they are trying to start implementing food aid and garden in-a-sack project trying to improve nutrition, offer security and income-generating opportunities, e.g. positive environmental impacts.

To realise this, the following project implementation and monitoring plan will be followed:

- Identification of vulnerable beneficiaries in South Africa.

- Community sensitization to garden-in-a-sack technology

- Demonstration sessions on preparation of sack garden

- Distribution of seedlings, monitoring and follow-up support to beneficiary house hold

- Capacity building of beneficiaries through training on nursery production practises, field management, composing, organic/low cost pest and disease control

\subsubsection{Challenges for Students}

- Limited spaces available

- Damage to sacks, crops from stray animals, pest and diseases

- Sustainable access to inputs such as soil, manure, seedlings and water 
Recent studies on UA and its impact on nutrition focus on dietary diversity and kilocalorie consumption as two main aspects which influence the outcome of improved nutrition (Guvatt et al, 2011). In his analysis of child nutrition and UA in Kampala, David (2011) also connected the aspect of maternal care to UA, arguing that mothers engaged in UA, as opposed to other forms of non-farm employment away from home, have an increased ability to care for their children. This was in return believed to positively impact levels of child nutrition. However, even proponents of UA highlight the fact that there is currently no detailed, empirical evidence for UA's impact on nutrition levels. This is also brought up for discussion in the International Food Policy and Research Institute's discussions on the links between UA and nutrition (Darrin, 2009)

Secondly, UA is assumed to create an 'opportunity cost' - domestic producers can either save income, via the consumption of home-produced foodstuffs that are cheaper to produce than to buy from the market, and/or increase income by selling or trading their products. Addressing urban food insecurity therefore requires a balancing act between urban agriculture (the opportunity cost of producing your own food) and more efficient urban food markets (making the food you buy cheaper). The latter may be a result of urban or peri-urban farmers' contributions to the markets. Higher cash income at the household level is then positively linked to food security as households are believed to have greater access to food products, both in terms of quantity and quality. This relationship however, to large extent, depends on the calorie elasticity of income - that is, the extent to which a change in income leads to a meaningful change in calorie intake. Households with low-income elasticity, for example, might not experience improved levels of nutrition linked to an increase in income. Given the low input costs of UA, most scholars nevertheless believe it to have great potential in addressing urban poverty and food insecurity.

\subsection{Self-employment}

Self-employed people are happier about their work -life balance even though they work the longest hours because they have more control over their time. They take responsibility for their own future, and take control of their own destiny. Urban agriculture can create self -employment and income that can be a significant but often uncertain contribution to household support. Self -employment in home and community gardens may strengthen self-esteem. Self -employment is to create an abundance of food for people in need by supporting and encouraging the establishment of gardens on unused land and space while increasing diversity raising awareness for health and wellness and inspiring and educating.

UA allows students to create an economically sustainable system to uplift communities around them. One of the aims of teaching agriculture in schools is to create an abundance of food for all in our generation. The intention is to affect a paradigm shift in the way that our world approaches food security, financial security is to empower people who are unemployed, underemployed, laid off, malnourished, have unhealthy diets, suffer from hunger or food insecurity. Growing your own food is important and inspires students. Urban agriculture connects students to opportunities so that they may move from stagnant difficult conditions to vibrant healthy and productive lifestyles, this includes connecting them to information, training and educational opportunities.

Agriculture is the way of life for most people in the South Africa. The vast majority of cultivated land is used by small farmers for subsistence agriculture which does not promote commercial value to boost the economy of the country. Students will develop fear on future job availability after graduating. Judging from the products of some secondary schools in the village, the gateway to tertiary institutions is the Agricultural Sciences which is not taken up to tertiary level. Matriculates with Agricultural Sciences as one subjects passed at matriculation level are not motivated to practice the Agricultural knowledge acquired at school. Number of factors that may come to play include, but not limited to the following: way of living, lack of arable land, land deterioration etc.

The cultivation of urban land is significant because it is seen as a palliative for underemployed through its connections with the food preparations. Urban agriculture can create employment in both the informal and formal industrial sectors. A training ground for students' entrepreneurs, urban agriculture as we have seen, is especially important as a source of supplementary food and income for households headed by students. In addition, however, many students may use it as their entry into the commercial world of South Africa's informal sector, e.g. by setting up kiosk in the industrial areas and serving prepared food grown on their own plots in the location. The experience of conducting these businesses has an impact on students and overcoming the major impediments of lack of education and alternative business experience opportunities. Students not uncommonly co-operate in these ventures may have come to recognise.

\subsection{Food Security}

Urban agriculture has been successful strategies for improving food access to food insures areas (David, 2011). Despite 
the fact that studies have shown that urban agriculture cannot provide all the nutritional needs of communities, it can be an effective way to take direct action and can catalyse more comprehensive food-access strategies. Urban agriculture food projects evaluated by the Community Food Security Coalition produced 18.7 million pounds of food with over 726,000 pounds donated for community food consumption (Higgins et al, 2011).

Food security means that all people at all times have physical and economic access to adequate amounts of nutritious, safe and cultural appropriate foods, which are produced in an environmentally sustainable and socially just manner, and that people are able to make informed decisions over their food choices.

Food security also means the people who produce our food are able to earn a decent living wage, growth, catching, producing, processing, transporting, retailing, and serving food. The contribution of urban agriculture to food security and healthy nutrition is probably its most important asset. Food production in the city is in many cases response of the urban poor to inadequate, unreliable and irregular access to food and the lack of purchasing power. The costs of supplying and distributing food from rural areas to the urban areas or the import food for cities are rising continuously and it is expected that food insecurity will increase. Access to nutritious food both economically and geographically is another perspective via in the effort to locate and livestock production in cities.

With the tremendous influx of world population to urban areas, the need for fresh and safe food is increased. The Community Food Security Coalition (CFSC) defines food security as; all persons in a community having access cultural acceptable, nutritionally adequate food through local, non-emergency sources at all times. Areas faced with food security issues have limited choices, often relying on highly processed fast food or convenience store foods that are high in calories and low in nutrients, which may lead to elevated rates of diet related illness such as diabetes. These problems have brought about the concept of food justice which (David, 2009) explain is places access to healthy, affordable, culturally appropriate food, the contexts of institutional racism, racial formation and racialized geographies. Food justice serves as a theoretical and political bridge between scholarship and activism on sustainable agriculture food insecurity and environmental justice. Global food security will remain a worldwide concern. Recently, crop yield has fallen in many areas because of declining investments in research and infrastructure as well as increasing water scarcity.

Climate change and HIVIAIDS are also crucial factors affecting food security in many regions. Food security in developing cities could be substantially improved by increased investments and policy reforms. Because HIVIAIDS negatively impacts on the food security status of households, it is crucial to identify how households respond to these impacts in order to identify positive food security entry points and design strategies that can effectively alleviate food insecurity amongst the households of people living with HIVIAIDS. We are also interested to study to establish hoe HIVIAIDS affected households in urban areas in terms of response to food shortages and interrelations between the practice of agriculture in order to help households within and around villages. (David, 2011). Food security, access to food aid and dietary diversity among these households are major concern. Food picked right from the ground and eaten is healthier than food that has travelled. It is therefore imperative that backyard farming is very important because it promotes wealthy creation of food.

\subsubsection{Two key pathways for UA to Food Security}

\subsubsection{Critics of urban agriculture}

Although Mougeot (2006) claims that "little could be found in the academic literature which would condemn urban agriculture at large and advocate its ban under any form", and despite presenting hostile urban planners and policy makers as the main critics of urban agriculture, the concept is not as universally supported as Mougeot wishes the reader to believe. The absence of reliable empirical data on the scale and impact of urban agriculture, must be named as one of the main limitations of urban agriculture, and may also explain urban planner's reluctance to embrace the concept. The above cited number of 800 million people involved in urban agriculture, globally provides good insight into the quality of research regarding urban agriculture.

Urban agriculture capital, a recent baseline study by the African Food Security Urban Network (Higgins et al 2011) found that only three percent of households in Lusaka currently use urban agriculture as a livelihood strategy. The same problem arises with regards to believed impact of urban agriculture and urban livelihoods. Stephan and David (2012) pointed to the absence of control groups in research regarding urban agriculture's impact, and criticise that "urban agriculture claims too much by equating all food production in towns with improved food security for poor people

Apart from the perceived absence of empirical evidence on urban agriculture, scholars have also pointed to urban health risks associated with urban agriculture and the implications of these for the environment. The usage of waste water, for example, is feared to contaminate produced food and intensive irrigation might lead to the spread of malaria 
and water borne diseases, as well as lowering the water table (Axumite, 1994). Soil erosion and the intensive use of fertilizers and pesticides might also present health risks to urban populations, as well as cause environmental harm. Furthermore, both large- and small-scale food productions are associated with deforestation, draining of water reservoirs, etc. In addition to that, Axumite believes that urban agriculture often excludes the most vulnerable groups in society through a lack of legal tenure, capital and policy support. Land use planning in urban areas often implies that once land that has been used for urban agriculture rises in value, the land is removed from agricultural use (Darrin, 2009). Only if and when city administrations set aside dedicated pieces of land for urban agriculture with low opportunity costs to those intending to use it, will potential users be able to use it for improved access to food or in order to generate income.

Furthermore, evaluations of the value of urban agriculture must consider the value of alternative uses of this land. Some go so far as to question whether urban agriculture is an oxymoron and although they conclude otherwise - that urban agriculture has the potential to improve urban lives - the evidence presented is limited and not systematically reviewed. As a result there is very little reliable knowledge on the actual scale of urban agriculture and its impact on urban livelihoods. It is also uncertain as to whether urban agriculture has a positive impact on urban livelihoods, which types of households are able to benefit from it, and whether urban agriculture's negative side effects outnumber its positive contribution

\subsection{Poverty eradication}

Eradication of poverty cannot be brought about by charity, but needs first and foremost empowering the poor, focussing on students, and tapping their tremendous potential. Students fall into poverty more easily and more frequently than adult, they constitute majority of the people living in poverty. Productive employment, including self - employment, played a central role in poverty eradication, access of the poor to land; capital and other productive resources must be improved. Hunger and malnutrition are the worst manifestation of poverty. The chronically hungry cannot grow out of poverty; this is morally reprehensible and economically wasteful. Efforts should be redoubled to reduce the proportion of under nourished by half of 2015. Poverty eradication and environment protection should be mutually supportive. (David, 2011)

How does Urban Agriculture help to address urban poverty? There are two arguments for the role of urban agriculture in addressing poverty. First, it provides some form of livelihood for low- skilled people. Though urban agriculture will not solve all poverty problems, systematic support could help to make some contribution in this regard. Urban Agriculture is one of many survival strategies that poor people use and its role in this regard should be acknowledge within the above context of job loss, persistent poverty, food shortages and rising food prices, students are busy starting their small plots projects trying to alleviate this problem. Scarcity of food, adequate nutrition which is needed by the body for a healthy normal life that easily resists life's stresses and strains

Urban agriculture project that involves disadvantaged groups such as orphans, disabled people, recent immigrants without jobs or older people, the aim is to integrate them more strongly into the urban network and to provide them with a decent livelihood. There are many social benefits that have emerged from urban agricultural practices such as improved overall social and life satisfaction or emotional well-being, improved health and nutrition, increased income, employment, food security within the household, and community social life.

Urban agriculture can have a large impact on the social and emotional well-being of individuals. Individuals report to have decreased levels of stress and better overall mental health when they have opportunities to interact with nature through a garden. There have been many documented cases in which community gardens lead to improved social relationships, increased community pride, and overall community improvement and mobilization. This improvement in overall community health can also be connected to decreased levels of crime and suicide rates. Urban gardens are often places that facilitate positive social interaction, which also contributes to overall social and emotional wellbeing. Many gardens facilitate the improvement of social networks within the communities that they are located. For many neighbourhoods, gardens provide a symbolic focus which leads to increased neighbourhood pride.

When individuals come together, physical activity levels are often increased. Everything that is involved in starting and maintaining a garden from turning the soil to digging holes, contributes to an individual's physical activity. Many state that working in agriculture is much more interesting and fulfilling than going to the gym, and that it makes getting exercise fun. In addition to the exercise that individuals receive while actually working in gardens many people say that the majority of the exercise they receive through Urban Agriculture is actually getting to the gardens. Many people either walk or ride their bike to the cities which provide many physical benefits.

Taking part in such practices is seen mostly as informal activity, but in many cities where inadequate, unreliable and irregular access to food is a recurring problem, urban agriculture has been a positive response to taking food concerns. The ability to produce and grow food for oneself has also been reported to improve levels of self-esteem of 
self-efficacy. Households and small communities take advantage of vacant land and contribute not only to their household food needs but also the needs of their resident city.

Community and residential gardening as well as small scale farming, save household food dollars, they promote nutrition and free cash for non-gardening foods and other items. This allows families to generate larger incomes selling to local groceries or to local outdoor markets while supplying their household with proper nutrition of fresh and nutritional produce. Studies have shown that participation from women have a higher production rate, therefore producing the adequate amount for household consumption while supplying more for the market It was decided at the Presidential Jobs Summit that the existing social security system will be reviewed and an effective comprehensive system aimed especially at those living in poverty and the unemployed, will be planned, developed and implemented. No universal cash benefits exist in pure form in South Africa.

Mougeot (2006) mentions the most important cash benefits in the form of means -tested payments to protect against particular stages of the life cycle and certain contingencies. These are:

- Means-tested pensions for the elderly, disabled, blind and war veterans and military pensions referred to as social pensions.

- Maintenance grants, which are means -tested allowances that are paid to children, parents and foster -parents under certain conditions

- Family allowances targeted at the working poor with large families (these are being phased out)

- Insurance -based benefits that are paid under the Unemployment Insurance Act and the Workmen's Compensation Act

\subsection{Economic factors}

Growing your own food saves household expenditures on food; poor people in poor countries generally spend a substantial part of their income (50-70\%) on food. Although the extent of the unemployment problem has been on the increase for the last two decades, it became particularly visible after 1994 which resulted in a large scale migration of native Africans from rural to metropolitan areas in predominantly fruitless search for work. This has resulted in the failure of the economy to provide jobs for the unemployed.

While a great deal of attention is presently being given to the attainment of political democracy, the crucial issue of economic democracy is being neglected. It is essential that decision-makers be sensitive to the complex relationship which exists between political freedom and economic development. If left unattended, economic problems such as unemployment could serve to upset the best of political solutions (Stephan \& David, 2012). The basic tenet of an employment creation strategy is that it has to attempt to direct the economy towards a more labour intensive, high economic growth path. A strategy consisting of four elements is recommended:

\subsubsection{Macro-economic stability: without this stability the effectiveness of any economic strategy will be diminished.}

Labour supply policies: firstly the supply of labour should be diminished, mainly by reducing population growth. This is clearly difficult to implement and is a long term solution. Secondly the quality of the labour force has to be improved in terms of its skills and productivity levels. There is a mismatch in the demand for and supply of labour in South Africa in that there is a surplus of unskilled labour and a shortage of highly skilled labour. Education, training and other productivity improving measures can minimise this mismatch and improve the productive capacity of the economy.

\subsubsection{Income redistribution}

policies aimed at the redistribution of income can direct the economy on to a more labour intensive growth path and improve the country's long term balance of payments position. This is because poor people tend to buy locally manufactured goods which have labour intensive production methods. If the size of the local market is increased by way of redistribution, manufacturers will be able to benefit from economies of scale which will mean in turn that they can compete more effectively on international markets.

\subsubsection{Small business development}

Small businesses in both the formal and informal sectors of the economy should receive special attention as their 
employment creation potential is well proven. The development of small businesses is an important means of economically empowering the poorer sector of the population. It also insures that the benefits of the increased purchasing power of the poorer communities.

One of the prerequisites for an effective employment creation strategy is to ensure that the factors which contributed to past unemployment are addressed as far as possible. Unless attempts are made to curb the effect of these factors on unemployment, they might continue to undermine any proposed strategy.

Urban agriculture has been proven to combat these economic issues in such a way that it frees the poor and the previously disadvantaged now unemployed individuals. This form of agriculture also contributes in the turnaround time for any job seekers. Peace of mind and liberty to live in abundance is any human's desire, but due to circumstances those luxuries only remain in our fantasies. With the efforts of having a greener environment such initiatives assist in the education of people coming from disadvantaged communities, they might not understand what the Ozone layer is or how solar panels work but the bit they can do will contribute a lot to sustain our environment, through urban agriculture.

\section{Conclusion}

In most townships the youth considers agricultural practices as an 'uncool' form of generating food. Everything needs to be from the store, and they are flashy about which store to go buy from. Such mind-sets have unfortunately been influenced by media and the lack of principles being taught at home by their elders.

They would rather go hungry, even though they have a piece of vacant land they could utilise. For many researchers that is very upsetting because we are raising future leaders and states man whom believe the earth is only good enough to be misused and nothing given back to it. This fast paced world that we live in has blinded people in appreciating the smallest and valuable things about life. The wonders created on this earth for us to live a life of abundance. Urban Agricultural practices ensures that we redirect all that thinking, fall in love with nature and appreciate the produce, that the very soil we walk on and take for granted, can produce. It is up to us to insure that we sustain our planet for the next generations that will walk this earth 200 years from now.

Another term frequently associated with life satisfaction is "well-being". This sometimes referred to more specifically as subjective well-being or social psychological well-being (Darrin, 2009). According to him, well-being is assessment of the general effective experience of older persons, in terms of a positive-negative continuum.

\section{Recommendations}

The South Africa Government should make agriculture education as a compulsory subject for grade 10 and grade 11 students. This will enable them to develop entrepreneurial skills and self-sufficient mentality before they finish their secondary school careers. The subject will also help them in building job skills, improving self-esteem and contributing to community revitalization. Similarly, the practical components of this subject should constitute $50 \%$ if not more from the overall marks. Hence, leaving secondary schools will no longer be a mirage and nightmare all because of no employment. However, some challenges were highlighted this include; limited spaces available, damage to sacks and crops by stray animals, pest and diseases, sustainable access to inputs such as soil, manure, seedlings and water.

\section{References}

Axumite G. Egziabher (1994) Cities Feeding People: An Examination of Urban Agriculture in East Africa. IDRC Publications. E-ISBN: 155250-109-4

Darrin N. (2009) Public Produce: The New Urban Agriculture. Island Press. ISBN-13: 978-1597265881

David S. Waller (2009) Genetically Modified Organisms, Consumers, Food Safety and the Environment. FAO Ethics Series. http://www.fao.org/85C0BF09-CBAC-4AA5-9279-4BD05C849BF2/FinalDownload/Downloadld-A936EA9F3472B5FB1AA786DC 9666F1BA/85C0BF09-CBAC-4AA5-9279-4BD05C849BF2/3/a-x9602e.pdf

David Tracey (2011) Urban Agriculture: Ideas and Designs for the New Food Revolution. New Society Publishers. Amazon books ISBN13: $978-0865716940$

Guvatt G.H, Oxman A.D, Schuenemann H.J, Tugwell P, \& Knottnerus A (2011): Grade guidelines: A new series of articles in the Journal of Clinical Epidemiology. 64 (4). Pp. 380-382

Higgins J.P.T, Altman D.G, Gøtzsche P.C, Jüni P, Moher D, Oxman A.D, Savovic J, Schulz K.F, Weeks L, \& Sterne J.A.C (2011): Cochrane Bias Method Group. Cochrane Statistical Methods Group. BMJ, 342(5928) http://www.ruaf.org/publications/citiesfarming-future- urban-agriculture-green-and-productive-cities

Mougeot, J. A. (2006) Growing Better Cities: Urban Agriculture for Sustainable Development. IDRC Publications ISBN: 1-55250-226-0 / 
118 pages.

Rene V. V. (2006). Cities farming for the future. RUAF Foundation, IDRC and IIRR publishing

Stephan J, G, \& David A, (2012) The Economic Imparts of Self-Employment. Journal of Agricultural and Applied Economics, 44 (3) Pp.315-321

Stewart R, van Rooyen C, Dickson K, Majoro M, de Wet T (2011). What is the impact of microfinance on poor people? A systematic review of evidence from sub-Saharan Africa. London: EPPI-Centre, Social Science Research Unit. University of London

Stewart R, van Rooyen C, Korth M, Chereni A, Rebelo Da Silva N, de Wet T (2011). Do micro-credit, micro-savings and micro-leasing serve as effective financial inclusion interventions enabling poor people, and especially women, to engage in meaningful economic opportunities in low- and middle-income countries? London: EPPI-Centre, Social Science Research Unit. University of London Available for download here: http://eppi.ioe.ac.uk/cms/Default.aspx?tabid=3352 